\title{
Effect of Technological Waste on Rheological Properties of the Polymer Compo- site
}

Jozef Dobransky, Martin Pollak, Marek Kocisko, Monika Torokova, Jakub Kascak

Faculty of Manufacturing Technologies with a seat in Presov, Technical University of Kosice. Bayerova 1, 08001

Presov. Slovak Republic. E-mail: jozef.dobransky@tuke.sk

The production of automotive products from polymeric materials represents operations associated with the flow of material during its shaping to the desired final mold. The technological aspects of the processing of polymeric materials are closely related to the rheological properties. The article deals with adding technological waste from production to virgin material and its influence on rheological or flow properties of selected polymer composite. The analyzed material is used in the manufacture of components (connectors) in the automotive industry. The rheological properties were measured in two stages. In the first stage, rheological properties were assessed in the short term immediately after preparation of the test samples. In the second stage, half of the samples were exposed to elevated temperature and the effect of aging on the rheological properties of the material was monitored. Based on measured MVR values before exposure to elevated temperature, it can be said that the amount of process waste does not significantly affect the flow properties of the polymer. After exposure to elevated temperature, there is a significant decrease in polymer flow properties probably due to the crystallization of the macromolecular chain.

Keywords: Rheological properties, Composite, Automotive, Technological waste

\section{Introduction}

The manufacture of articles made of polymer composite materials represents operations associated with the material flow during shaping of the material into the finished product final mould. The rheology of polymers constitutes a complex branch of industry. In their diversity of structure, molecular weight, including weight distribution, different polarity, the existence of intermolecular interactions, polymers represent materials with a great variety of properties. The rheological characteristics are closely related to the technological aspects of polymer processing, because most of the processing technologies of polymer materials are based on their processing in the melt, where the polymer flow or its deformation occurs in the melt or in the solid state. [1], [2]

In order to establish the processing properties of polymeric materials, it is necessary to know the properties that affect such materials' susceptibility to physical and chemical changes in structure and the properties demonstrating themselves in course of processing polymeric materials. The processability thus defined is of great practical importance, and knowledge of the same is applied to the polymeric material processing. Typical for workability are parameters the certain properties of which are established under certain conditions. The knowledge of these indicators makes it possible to obtain a comprehensive picture of the material's processability. [3-5]
The Melt Flow Index (MFI) is an important component of overall information about the correct processing of polymers, as well as information on the selection of technological parameters in the process of their processing. The MFI value is reported by all manufacturers of thermoplastic granules and is one of the key indicators of the thermoplastic materials classification. [6]

Several factors influence the polymer flow properties. The most important of them are the polymer's chemical and molecular structure. Thus, by determining the melt viscosity, the degree of polymer degradation can be evaluated indirectly. Due to the fact that the polymer melt is a pseudoplastic material, it is preferable to assess the melt's flowability instead of its viscosity. In industrial practice, the method of establishing the melt index for this purpose has proved to be effective when done at the initial inspection in the production plants. [7]

The recycling process in the production plant is an effort to eliminate plastic waste with the help of the so-called waste-free technological processes. This is a production process that involves comprehensive use of raw materials and energy in the cycle so that no impact on the environment interferes with the environment's normal functioning. This effort to emulate the natural cycle in the planning and management of industrial enterprises also requires changes in the economic system. So far, waste-free technology remains at the level of theoretical considerations or is applied in 
the design and subsequent implementation of new production processes. [8], [9]

Therefore, the current trend is to apply recycling principles in terms of the treatment and re-use of waste already generated. This faster and yet simpler option is enabled by development and deployment of recycling technologies. The main feature of recycling technology is its relative independence in the technological layout. [10], [11]

The aim of the present paper is to assess the effect of the addition of technological waste to the virgin material on the flow properties of the polymer composite. This effect was monitored in two phases. In the first phase, the impact was assessed in the short term and in the second phase, it was assessed from the long term perspective.

Tab. 1 Basic material properties of the tested material [12]

\begin{tabular}{|c|c|c|}
\hline Physical properties & Value & Unit \\
\hline Density & 1650 & $\mathrm{~kg} / \mathrm{m}^{3}$ \\
\hline MVR volume flow index $\left(275^{\circ} \mathrm{C} / 2,16 \mathrm{~kg}\right)$ & 22 & $\mathrm{~cm}^{3} / 10 \mathrm{~min}$ \\
\hline Absorbability & 0.4 & $\%$ \\
\hline Viscosity number & 108 & $\mathrm{~cm}^{3} / \mathrm{g}$ \\
\hline Mechanical properties & Value & Unit \\
\hline Tensile elasticity modulus & 11300 & $\mathrm{MPa}$ \\
\hline Breaking stress & 145 & $\mathrm{MPa}$ \\
\hline Elongation at break & 3.2 & $\%$ \\
\hline Creep module in tension & 7500 & $\mathrm{MPa}$ \\
\hline Charpy impact resistance $\left(+23^{\circ} \mathrm{C}\right)$ & 60 & $\mathrm{~kJ} / \mathrm{m}^{2}$ \\
\hline Charpy impact resistance $\left(-30^{\circ} \mathrm{C}\right)$ & 55 & $\mathrm{~kJ} / \mathrm{m}^{2}$ \\
\hline Notched Charpy impact resistance $\left(+23^{\circ} \mathrm{C}\right)$ & 10 & $\mathrm{~kJ} / \mathrm{m}^{2}$ \\
\hline
\end{tabular}

Before the experimental measurement, it was necessary to prepare the test bodies, which consisted of mixing recycled material in the form of pulp with the virgin granulate. Mixing was carried out manually in a specified amount corresponding to the recycled content in the virgin material of $0,10,20,30,40,50,60$, 80 and 100 weight percent, respectively. From the mixture (batches) prepared in this way, multipurpose type $A$ test specimens were injected according to STS EN ISO 3167 or $1 A$ according to STS EN ISO 5272. These specimens were subsequently used to establish the mechanical properties.

The injection moulding process was carried out on a standard Demag D 60 - 182 injection moulding machine of a column structure at JMP Plast. The material was dried according to the conditions given in the relevant material data sheet before processing and testing. At the end of the production cycle, all specimens were conditioned under standard conditions of $23 / 50$. From the bodies prepared in this way, the granulate

\section{Description of the material and the met- hods used}

This chapter provides a detailed description of the test material and the research methods that were necessary to apply to achieve the results.

\subsection{Material description and test samples preparation}

A polymer composite with the trade name of U1tradur B 4406 G6 Q717 was chosen as the test material. A composite with the polymer matrix PBT (polybutylene terephthalate) filled with $30 \%$ glass fibres is intended for production of components for automotive industry by injection technology. It is designed for products requiring increased resistance to burning (potentiometer parts, plugs and sockets of connectors, switches, etc.). An overview of the basic material properties of the composite is given in Table 1. 
quickly evaluate the quality of the input material and hence eliminate the production of nonconforming parts. The method can also be used to monitor adverse effects of high processing temperatures and shear stresses on the product's molecular structure. The test is performed using a so-called extrusion rheometer, which is a measuring device.

The principle of the method is to establish the mass or volume of the polymer melt that is extruded from a rheometer cylinder by a nozzle of defined dimensions under predetermined temperature and load conditions. The melt flow index is expressed in grams per ten minutes $(\mathrm{g} / 10 \mathrm{~min})$ and is referred to as the melt mass flow index, or in cubic centimetres per ten minutes $\left(\mathrm{cm}^{3} / 10 \mathrm{~min}\right)$ and is referred to as the melt volume rate. The method of establishing the mass or volume melt flow rate is described in detail in the international standard STS EN ISO 1133-1. [14]

Measurement of melt flow volume rate was performed at the Technical University of Liberec, Faculty of Mechanical Engineering, Department of Engineering Technology. The extrusion rheometer at which the measurement was made is shown in Fig. 1.

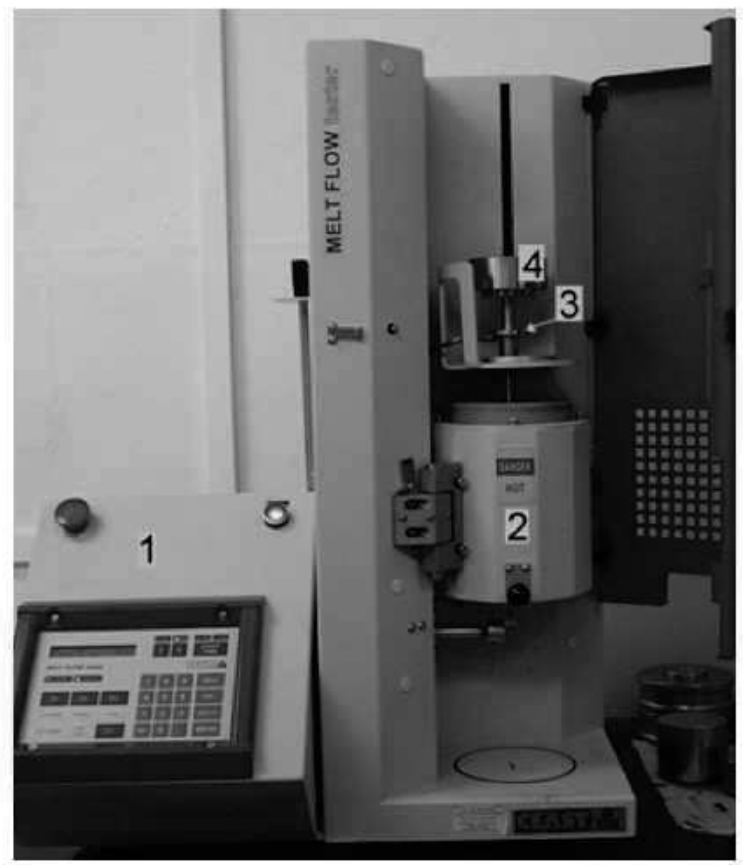

Fig. 1 MeltFlow Index Tester extrusion rheometer (1 control panel, 2 cylinder, 3 piston, 4 weights)

A sample from each batch to be measured was crushed to smaller particle size to fit into the extruder rheometer cylinder. The test material had been dried in a Binder VD 53 vacuum oven at $130{ }^{\circ} \mathrm{C}$ for 14 hours prior to measurement. After drying, its residual moisture was checked on a Metler Toledo HX 204/M moisture analyser. Before starting the measurement, the working cylinder of the apparatus was allowed to warm to $275{ }^{\circ} \mathrm{C}$ for at least $15 \mathrm{~min}$. The device was then calibrated using a calibration roller. Subsequently, the comminute dried material was dosed into the cylinder and manually pressed by a rod to prevent the presence of atmospheric oxygen. [15]

Preheating was carried out with a piston weighing 2.16 $\mathrm{kg}$ for $5 \mathrm{~min}$. After this time, the nozzles were opened, and the evaluated polymer was allowed to flow freely. The measuring device recorded the time required to move the piston along a specified path that was used to calculate the melt flow index. [16], [17]

\section{Description of the achieved results}

The melt volume rate (MVR) was measured in accordance with STS EN ISO 1133-1. The graphical dependence of MVR on mass ratio of technological waste in virgin material was compiled from the MVR values obtained. As has been mentioned, the measurement took place in two phases. In the first phase, short term rheological properties were assessed immediately after the test samples had been prepared. In the second phase, half of the samples were exposed to elevated temperature and the effect of aging on the material's rheological properties was observed.

Based on the measured values and generated graphical dependence of MVR on the weight ratio of technological waste in the virgin material, which is shown in Fig. 2, it can be said that with an increasing weight ratio of the technological waste in the mixture, no significant increase in the melt flow rate values occurs. Figure 2 shows the mean values of the melt flow index MVR with error bars, which represent the standard deviation of the measured values.

The PBT_V label in the graph represents a batch of virgin material that has not been thermally degraded. Technological waste in the form of recycled material was added to this material. The virgin material had an MVR value of $23 \mathrm{~cm}^{3} / 10 \mathrm{~min}$. The PBT_R label indicates a batch of recycled material that has been made from virgin material. This recycled material was then added to the virgin material in the stated percentages. The MVR value of the recycled material was $27.1 \mathrm{~cm}^{3} / 10 \mathrm{~min}$. For a material with zero technological waste ratio, the MVR was $37.6 \mathrm{~cm}^{3} / 10 \mathrm{~min}$. The addition of additional amounts of technological waste resulted in a slight increase in MVR. The highest value was recorded when the technological waste accounted for $60 \%$ of the mixture, which is represented by the value of $44.3 \mathrm{~cm}^{3} / 10 \mathrm{~min}$. The MVR value at $100 \%$ technological waste was $41.9 \mathrm{~cm}^{3} / 10 \mathrm{~min}$.

Fig. 3 shows the MVR dependence on the mass fraction of technological waste in virgin material after exposure to elevated temperature with error bars, which represent the standard deviation of the measured values. As can be seen in Figure 3, due to the action of activation energy during the aging process of the parts $(500 \mathrm{~h})$, there is a significant reduction in the MVR value and a decrease in the life of the parts due 
to the presence of recycled material in the virgin material.

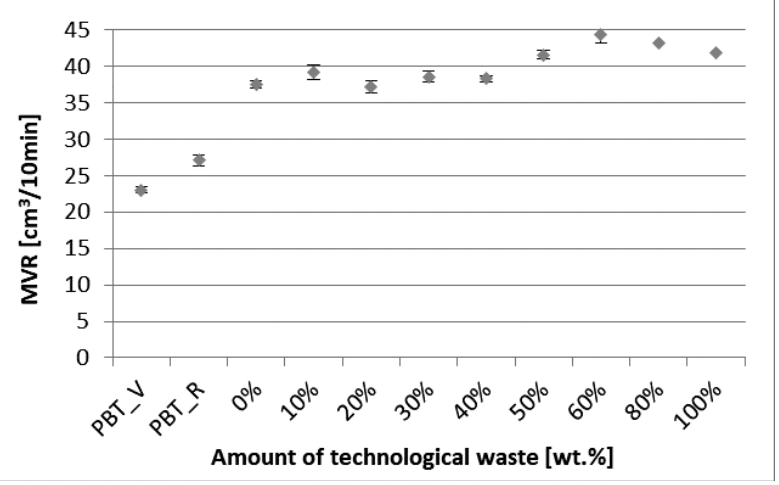

Fig. 2MV R dependence on the technological waste weight ratio before exposure to elevated temperature

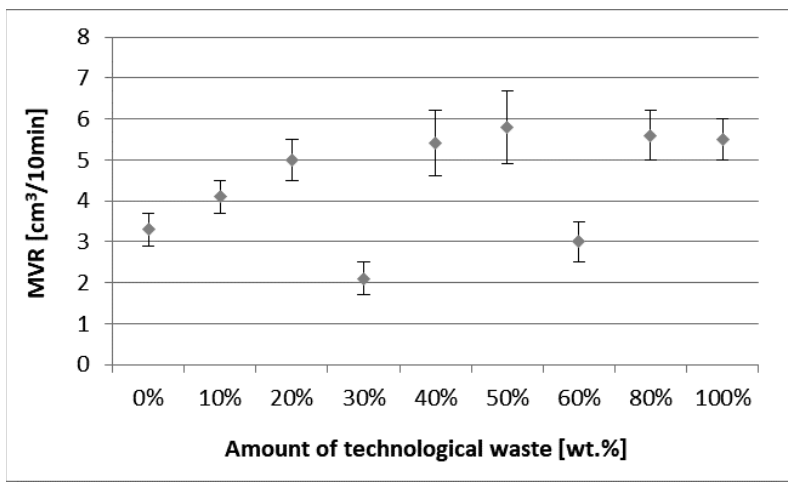

Fig. $3 \mathrm{MV} \mathrm{R}$ dependence on the technological waste weight ratio after exposure to elevated temperature

At zero technological waste, the MVR value dropped from $37,57 \mathrm{~cm}^{3} / 10 \mathrm{~min}$ to $3,34 \mathrm{~cm}^{3} / 10 \mathrm{~min}$, a decrease of $91,1 \%$. For other percentages of technological waste in virgin material, the MVR values showed identical differences. This is probably due to the additional recrystallization of the macromolecular chain, since the composite material at hand is a semicrystalline polymer.

\section{Conclusion}

The aim of the paper was to assess the effect of the addition of technological waste to the virgin material on the flow properties of the polymer composite in the production of components for the automotive industry. The research was divided into two phases. In the first phase, the impact of adding technological waste to the virgin material was assessed in the short term. In the second phase, the impact of the addition was assessed in the long term, i.e. from the aspect of the parts' service life. It follows from the values measured and from the graphical dependencies that no significant increase in the values of volume index of melt flow occurs with increased weight ratio of technological waste in the mixture. Thus, it can be stated that in reprocessing of the material, no degradation of the same occurs, i.e. no split and shortening of the macromolecular chain, which would be demonstrated in the melt's increased fluidity. A substantial drop in the material's fluidity was found in the second phase, which means that adding technological waste has no effect on the parts' service life.

\section{Acknowledgement}

This article was created thanks to the framework of the project VEGA no. 1/0026/19.

\section{References}

[1] GIGANTE, V., ALIOTTA, L., COLTELLI, MB., CINELLI, P., BOTTA, L., LA MANTIA, FP:, LAZZERI, A. (2020). Fracture behavior and mechanical, thermal, and rheological properties of biodegradable films extruded by flat die and calender. In: Journal of Polymer Science, Vol. 58, pp. 3264-3282.

[2] VITA, S., RICOTTI, R., DODERO, A., VICINI, S., BORCHARDT, P., PINORI, E., CASTELLANO, M. (2020). Rheological, mechanical and morphological characterization of fillers in the nautical field: the role of dispersing agents on composite materials. In: Polymers, Vol. 12, pp. 1339.

[3] GLOGOWSKA, K., SIKORA, J.W., DULEBA, B. (2015). Effect of mechanical properties of metal powder-filled hybrid moulded products. In: Journal of Polymer Engineering, Vol. 36, pp. 705-712.

[4] PORKODI, P., ABHILASH, JK., SHUKLA, HK., RAWAT, J. (2020). Rheological properties of concentrated polyacrylonitrile co-polymer and lignin blend solution. In: Polymer Bulletin, Vol. 77, pp. 3937-3951.

[5] VALASEK, P., RUGGIERO, A., MULLER, M. (2017). Experimental description of strength and tribological characteristic of EFB oil palm fibres/epoxy composites with technologically undemanding preparation. In. Composites Part B Engineering, Vol. 122, pp. 79-88.

[6] SAHLI, M., BARRIERE, T., ROAZARD, X., ASSOUL, M. (2020). Investigating mechanical, thermal and rheological properties of polypropylene/carbon nanotubes composites. In: Microsystem Technologies, Vol. 26, pp. 3023-3027.

[7] OVSIK, M., MIZERA, A., MANAS, M., HYLOVA, L., BEDNARIK, M., STANEK, M. (2018). The effect of irradiation on mechanical and thermal properties of selected types of polymers. In: Polymers, Vol. 10, pp. 1-22. 
[8] OVSIK, M., MANAS, D., MANAS, M., STANEK, M., HRIBOVA, M., KOCMAN, K., SAMEK, D., MANAS, M. (2012). Irradiated polypropylene studied by microhardness and waxs. In: Chemicke listy, Vol. 106, pp. 507510 .

[9] ZAJAC, J., DUPLAKOVA, D., HATALA, M., GOLDYNIAK, D., POKLEMBA, R., SOLTES, P. (2019). The effect of used fillers on the strength characteristics of polymer concrete test bodies. In: TEM Journal-Technology Education Management Informatics, Vol. 8, pp. 795800.

[10] BORUVKA, M., BEHALEK, L., LENFELD, P., NGAOWTHONG, C., PECHOCIAKOVA, M. (2019). Structure-related properties of bionanocomposites based on poly(lactic acid), cellulose nanocrystals and organic impact modifier. In: Materials Technology, Vol. 34, pp. 143-156.

[11] GRESKOVIC, F., SPISAK, E., DULEBOVA, L. (2006). The influence of the regrind on properties change of plastics, In: Acta Mechanica Slovaca, Vol. 10, pp. 135-140.

[12] HSISSOU, R., BEKHTA, A., DAGDAG, O., EL BACHIRI, A., RAFIK, M., ELHARFI, A.
(2020). Rheological properties of composite polymers and hybrid nanocomposite. In: Heliyon, Vol. 6, pp. e04187.

[13] MONKOVA, K., VASINA, M., MONKA, PP., KOZAK D., VANCA, J. (2020). Effect of the pore shape and size of 3D-printed openporous ABS materials on sound absorption performance. In: Materials, Vol. 13, pp. 4474.

[14] XI, L. (2019). Molecular simulation for predicting the rheological properties of polymer melts. In: Molecular Simulation, Vol. 45, pp. 1242-1264.

[15] HAJSMAN, J., JENICEK, S., KUCEROVA, L. A RIEGER, D. (2019). Microstructure and properties of polymer composites. In: Manufacturing technology, Vol. 19, No. 6, pp. 941-946. ISSN 1213-2489.

[16] NOVOTNY, J., JASKEVIC, M., LYSONKOVA, I. (2018). Mesocomposites based on the polymethylmethacrylate matrix. In: Manufacturing technology, Vol. 18, No. 5, pp. 799-804. ISSN 1213-2489.

[17] KALOVA, M., RUSNAKOVA, S. (2017). Microstructure of polymer composite materials. In: Manufacturing Technology, Vol. 17, No. 5, pp. 722-728. ISSN 1213-2489. 